\title{
Doença da arranhadura do gato (DAG) e a importância de um diagnóstico preciso: relato de caso clínico
}

\author{
Cat scratching disease and the importance of a precise diagnosis: case report \\ Enfermedad por arañazo de gato y la importancia de un diagnóstico correcto: \\ reporte de un caso
}

\author{
Dayane Goto NOVAIS \\ Charlene Corrêa MENDES \\ Bárbara de Lima SALLA \\ Giullia Novack Ferreira ROCHA \\ Cristine Moreira Silva BENETTI \\ Ciderléia Castro de LIMA \\ Breno César Diniz PONTES
}

Departamento de Medicina da Universidade José do Rosário Vellano (UNIFENAS), 37132-440, Alfenas, MG, Brasil

\begin{abstract}
Resumo
A Doença da Arranhadura do Gato cursa com linfadenopatia crônica e sintomas inespecíficos. No Brasil, é pouco lembrada no cotidiano da clínica médica, mas pode evoluir negativamente, com quadros mais graves. O objetivo do presente trabalho é descrever a importância do teste sorológico para o diagnóstico da doença, frente ao relato de caso do ambulatório de Infectologia da UNIFENAS, com parecer favorável do Comitê de Ética da Instituição (1070274). Diante de um amplo quadro de diagnósticos diferenciais da doença, destaca-se a relevância de anamnese detalhada e sorologia para Bartonella henselae, visando conduta terapêutica precoce evitar maiores complicações.

Descritores: Sorologia; Medicina Clínica; Diagnóstico.
\end{abstract}

\begin{abstract}
Cat scratching disease presents with chronic lymphadenopathy and non-specific symptoms. In Brazil, it is little remembered in the daily routine of the medical clinic, but it can evolve negatively, with more severe pictures. The aim of this paper is to describe the importance of the serological test for the diagnosis of the disease in view of the case report of the Infectology clinic of UNIFENAS, with favorable opinion of the Ethics Committee of the Institution (1070274). Considering the wide range of differential diagnoses of the disease, we highlight the relevance of detailed anamnesis and serology for Bartonella henselae, aiming at early therapeutic management to avoid further complications.
\end{abstract}

Descriptors: Serology; Clinical Medicine; Diagnosis.

\begin{abstract}
Resumen
La Enfermedad por Arañazo de Gato es una enfermedad que conduce a la linfadenopatía crónica y síntomas inespecíficos. En Brasil, es poco recordado en la clínica médica del día a día, pero puede desarrollarse negativamente, con la más severa. El objetivo del presente trabajo es describir la importancia de las pruebas serológicas para el diagnóstico de enfermedad, frente al relato de caso de la Clínica de Enfermedades Infecciosas Unifenas con el asentimiento del Comité de Ética Institucional (1070274). Considerando el amplio cuadro de diagnósticos diferenciales de la enfermedad, se destaca la relevancia de anamnesis detallada y serología para Bartonella henselae, buscando conductas terapéuticas precoz evitar mayores complicaciones.

Descriptores: Serología; Medicina Clínica; Diagnóstico.
\end{abstract}

\section{INTRODUÇÃO}

A Doença da Arranhadura do Gato (DAG) é relativamente comum nos Estados Unidos, representando a principal causa de linfadenopatia crônica na infância. No Brasil, existem poucos casos relatados, devido à não inclusão da DAG no diagnóstico diferencial de várias síndromes clínicas ${ }^{1}$.

Em nosso país a DAG não é uma doença de notificação compulsória, desta forma, torna-se inviável estimar a magnitude da patologia. Todavia, as condições climáticas favoráveis, ampla presença do reservatório animal e tendência à resolução espontânea, favorecem que a doença seja frequente no ambiente onde vivemos ${ }^{2}$.

Observamos, no entanto, que a falta de exames complementares mais acurados, a dificuldade em cultivar o patógeno e a necessidade do estudo histopatológico dificultam o diagnóstico ágil e contribuem para o não reconhecimento dessa enfermidade ${ }^{2}$. O propósito do presente trabalho é descrever a importância do teste sorológico no diagnóstico da DAG na prática da clínica médica.

\section{CASO CLÍNICO}

$\mathrm{O}$ presente estudo configura um relato de caso originado na Unidade de Infectologia, cujo médico assistente é vinculado à Universidade José do Rosário Vellano, Departamento de Medicina e foi aceito pelo Comitê de Ética da Universidade, pelo parecer: 1.070.274.

Paciente R.R.N, 42 anos, sexo feminino, médica veterinária, procedente do Sul de Minas Gerais, veio ao ambulatório de Infectologia encaminhada para investigação de febre. Há 20 dias iniciou quadro de indisposição e mal estar, associado a odinofagia e febre. Fez uso de AINE, que cursou com inapetência e urina escurecida, além de persistência da temperatura corpórea elevada. Devido à alteração urinária e febre, o médico anterior utilizou Ciprofloxacino empiricamente, pensando em Infecção do Trato Urinário (ITU). Dois dias após a utilização do medicamento, a paciente relata cefaléia intensa, dorsalgia e persistência da febre (temperatura axilar $38,5^{\circ}$ ). Além de turvação visual, dor, sensibilidade ocular e diminuição da acuidade visual, principalmente em olho esquerdo. Foi 
realizada ultrassonografia de abdômen total, que evidenciou esplenomegalia. Aos exames laboratoriais: VHS: $76 \mathrm{~mm} / 1$ hora; PCR: 46; $\mathrm{Hb}$ : 11,7g\%; Linfócitos: 12.450 com eosinofilia 8\%. AST e ALT normais; Sorologias: Ag Hbs negativo; Anti Hbs negativo; Anti HCV negativo, Anti HIV 1 e 2 não reagentes; CMV IgG positivo, IgM negativo; EBV IgG positivo; Toxo IgG positivo, IgM negativo. Após duas semanas de investigação, com hipótese diagnóstica de DAG, optamos por avaliação de Retinólogo em São Paulo, onde foi solicitada sorologia: Bartonella henselae $\operatorname{IgM}$ e $\operatorname{IgG}$ positivos; Bartonella quintana IgM e IgG negativos. Foi indicado tratamento com Doxiciclina durante 90 dias e corticoterapia. Após três semanas de medicação, observamos melhora clínica, com regressão dos sintomas visuais e febre, melhora da adinamia e retorno do apetite.

\section{DISCUSSÃO}

\section{o MANIFESTAÇÕES CLÍNICAS}

A Doença da Arranhadura do Gato (DAG) é causada pelo bacilo gram negativo Bartonella henselae, que tem como porta de entrada o local da arranhadura do felino. Este, por sua vez, não costuma manifestar sinais da doença.

A DAG é mais descrita em crianças, mas há frequentes casos em adultos ${ }^{2}$. A manifestação clínica é variável, desde assintomática até sua forma grave, podendo ser fatal. Entretanto, o sinal típico da doença é a linfadenite benigna, que é precedida de uma pápula ou vesícula não pruriginosa no local de inoculação do bacilo.

Os locais mais comuns de acometimento linfonodal é a região cervical, axilar e inguinal, podendo-se atingir também mais de uma cadeia linfática. No geral, não há manifestações flogísticas, mas podemos observar dor local leve ${ }^{5}$.

Entre outras manifestações gerais observamos cefaléia, naúsea, dor abdominal, vômito, anorexia, fadiga e febre, que pode prolongar-se por até 70 dias. Relata-se também algumas apresentações atípicas, como o acometimento da conjuntiva palpebral acompanhada de linfadenopatia ipsilateral pré-auricular, hepatoesplenomegalia e, mais raramente ainda, eritema nodoso, púrpura trombocitopênica e osteomielite ${ }^{4}$.

No caso dos imunossuprimidos, relata-se tremores, sudorese noturna, mialgia, anemia hemolítica, placas cutâneas hiperpigmentadas, nódulos subcutâneos e intensa linfangite ${ }^{4}$.

\section{- DIAGNÓSTICO}

Apesar da não existência de um método que seja padrão ouro para o diagnóstico da DAG, a sorologia para Bartonella henselae tem sido um dos métodos mais empregados, através dos testes de imunofluorescência indireta e imunoenzimático. A sensibilidade e especificidade do primeiro, gira em torno dos $88 \%$ e $97 \%$ respectivamente ${ }^{3}$.

A intradermorreação também pode ser empregada, porém apresenta restrição de uso aos quadros agudos, devido retardo da reação da imunidade celular. Biópsia da lesão ou gânglio é raramente indicada ${ }^{4}$.

Outras técnicas como a detecção genética por biologia molecular e microscopia também podem ser utilizadas, entretanto, trata-se de métodos pouco acessíveis à prática clínica, sendo reservados para pesquisa.

\section{- HISTOPATOLOGIA}

Histologicamente ocorre uma proliferação endotelial que se dispõe em lóbulos, os quais apresentam infiltrados inflamatórios de leucócitos ao redor dos agregados bacterianos e leucocitoclasia em seu interior. Também podemos observar granulomas com área necrótica central, circundada por linfócitos e histiócitos, com infiltrado neutrofílico formando microabscessos ${ }^{3}$.

\section{○ TERAPÊUTICA}

Nos casos de DAG com linfadenomegalia, a evolução da doença é autolimitada e a maioria dos pacientes evolu com remissão espontânea sem sequelas, não necessitando antibioticoterapia ${ }^{6}$. Nestas situações recomenda-se apenas tratamento de suporte ou das infecções secundárias da porta de entrada para Stafilococos sp e Streptococos $s p^{4}$.

O linfonodo pode evoluir para flutuação e supuração espontânea em $10 \%$ dos pacientes ${ }^{5}$. Nestes casos, os linfonodos supurativos devem ser drenados. Incisões de linfonodos não supurativos devem ser evitadas, podendo resultar em baixa tendência de cura 9 .

Dentre os vários antimicrobianos já utilizados para o tratamento da DAG, ainda não há consenso em relação às drogas de primeira escolha e qual a duração do tratamento. Macrolídeos são usualmente utilizados ${ }^{7}$. A Azitromicina, se administrada no primeiro mês de sintomas, durante a fase aguda, pode favorecer a diminuição do linfonodo ${ }^{8}$. Além destes, Quinolonas e Rifampicina podem apresentar um resultado benéfico, porém, limitado ${ }^{7}$.

Em casos graves, podem ser utilizados Tetraciclina, Cloranfenicol ou a associação de Sulfametoxazol com Trimetoprim ${ }^{4}$. O uso de Penicilinas e Cefalosporinas ainda é discutido, não sendo evidenciada ação contra a bactéria ${ }^{2}$.

O uso de corticosteroides como tratamento adjuvante ainda é discutível, esta terapia é sugerida para pacientes com um curso de longa duração. Contudo, ainda não há dados controlados a respeito?

\section{CONCLUSÃO}

O conhecimento das diversas formas da Doença da Arranhadura do Gato (DAG) torna-se importante para o estabelecimento de diagnóstico diferencial quando as queixas do paciente são inconclusivas, não se enquadrando a uma patologia específica. Para o médico, é importante perceber que em vista de uma sintomatologia inespecífica, junto às sorologias comumente utilizadas, o teste sorológico para DAG deve ser solicitado.

Além disso, este estudo tem relevância para o diagnóstico precoce, evitando maiores acometimentos sistêmicos neurológicos, oculares ou viscerais, e até mesmo o óbito. Por fim, futuramente a DEG pode ter sua real incidência estabelecida na população brasileira.

\section{REFERÊNCIAS}

1. Albuquerque KTP, Simões G, Carvalho FG. Doença de Arranhadura do Gato. Rev Médica, Rio de Janeiro. 2002; 36(2/3) Disponível em: http://www.hse.rj.saude. gov.br/ profissional/revista/36b/ gato.asp. Acesso em: 8 dez. 2016.

2. Souza GF. Doença da arranhadura do gato: relato de caso. Rev Med Minas Gerais. 2011; 21(1):75-8.

3. Velho PENF, Souza EM, Cintra ML, Moraes AM, Uthida-Tanaka AM. Diagnóstico da infecção por Bartonella spp.: a propósito de um caso de angiomatose bacilar. An Bras Dermatol. 2006; 81(4):349-53.

4. Coura JR. Dinâmica das doenças infecciosas e parasitárias. Rio de Janeiro: Guanabara; 2005.

5. Prado FC, Ramos J, Valle JR (eds.) Atualização Terapêutica. 23. ed. São Paulo: Artes Médicas; 2007.

6. Chondrogiannis K, Vezakis A, Derpapas M, Melemeni A, Fragulidis G. Seronegative cat scratch-disease 
diagnosed by PCR detection of Bartonella henselae DNA in lymph node samples. Braz J Infect Dis. 2012;16(1):96-9.

7. Ridder GJ, Boedeker CC, Technau-Ihling K, Grunow R, Sander A. Role of cat-scratch disease in lymphadenopathy in the head and neck. Clin Infect Dis. 2002; 35(6):643-9.

8. Azevedo ZMA, Higa LYS. Boechat PR, Boechat MB, Klaplauch F. Doença da arranhadura do gato por Bartonella quintana em lactente: uma apresentação incomum. Rev Soc Bras Med Tropical. 2000; 33(3):313-7.

9. Manfredi R, Sabbatini S. Bartonellosis: suggestive case reports in adult and pediatric patients and therapeutic issues. Braz J Infect Dis. 2006; 10(6):411-5.

\section{CONFLITO DE INTERESSES}

Os autores declaram não haver conflitos de interesse.

\section{AUTOR PARA CORRESPONDÊNCIA}

Cristine Moreira Silva Benetti

cristine_benetti@hotmail.com

Submetido em 02/03/2017

Aceito em 03/04/2017 